\title{
Respiratory support for premature neonates in the delivery room: effects on cardiovascular function and the development of brain injury
}

\author{
Graeme R. Polglase ${ }^{1,2}$, Suzanne L. Miller', Samantha K. Barton', Martin Kluckow ${ }^{3}$, Andrew W. Gill ${ }^{4}$, Stuart B. Hooper ${ }^{1,2}$ and \\ Mary Tolcos'
}

The transition to newborn life in preterm infants is complicated by immature cardiovascular and respiratory systems. Consequently, preterm infants often require respiratory support immediately after birth. Although aeration of the lung underpins the circulatory transition at birth, positive pressure ventilation can adversely affect cardiorespiratory function during this vulnerable period, reducing pulmonary blood flow and left ventricular output. Furthermore, pulmonary volutrauma is known to initiate pulmonary inflammatory responses, resulting in remote systemic involvement. This review focuses on the downstream consequences of positive pressure ventilation, in particular, interactions between cardiovascular output and the initiation of a systemic inflammatory cascade, on the immature brain. Recent studies have highlighted that positive pressure ventilation strategies are precursors of cerebral injury, probably mediated through cerebral blood flow instability. The presence of, or initiation of, an inflammatory cascade accentuates adverse cerebral blood flow, in addition to being a direct source of brain injury. Importantly, the degree of brain injury is dependent on the nature of the initial ventilation strategy used.

\section{PRETERM BIRTH AND THE REQUIREMENT FOR} VENTILATION

Preterm birth, defined as birth before $37 \mathrm{wk}$ of gestation, remains a worldwide problem. The infants at greatest risk are those born at $<29 \mathrm{wk}$ gestation-for whom mortality remains high and survival is associated with the greatest risks of neurodevelopmental impairment (1). Many infants born preterm are surfactant deficient and have immature lungs, with a small surface area and a thick air-blood barrier that impairs gas exchange (2). Consequently, preterm infants, particularly those born before $29 \mathrm{wk}$ of gestation, often require respiratory support at birth. The initiation of respiratory support in the delivery room, typically using intermittent positive pressure ventilation (PPV) via a face mask or after intubation, is often critical in ensuring a successful transition to newborn life. The primary aim of this respiratory support is twofold: (i) to aerate the lung and initiate pulmonary gas exchange and (ii) to trigger the circulatory transition from the fetal physiology into the newborn/adult physiology (3).

There is increasing evidence, however, that delivery of this respiratory support can be injurious to the preterm neonate. Importantly, although studies have focused on the immediate effect of respiratory support on the lung, evidence suggests that the effect of ventilation has downstream consequences for the preterm infant, particularly for the immature brain. Furthermore, this evidence indicates that the lung, heart, and brain are intrinsically linked during this transitional period (4), whereby lung injury or the initiation of an inflammatory response within the lung can have direct and indirect effects on the cardiovascular system, systemic circulation, and cerebral circulation. Indeed, the concept of multiple-organ interrelationships in ventilated patients with severe respiratory disorders is well established in the literature regarding adults $(5,6)$. However, although similarities between the association of brain injury and ventilation can be drawn between adults and preterm newborns, the uniqueness of the transitioning circulation at birth provides additional mechanisms/pathways for brain injury to occur.

The major pathways by which ventilation can lead to brain inflammation and injury in the preterm neonate are as follows: (i) altering pulmonary venous return and, subsequently, left ventricular output, resulting in rapid abnormal fluctuations to cerebral blood flow (CBF) and (ii) the initiation of pulmonary inflammation, which leads to a systemic inflammatory cascade (Figure 1).

\section{THE CARDIOVASCULAR TRANSITION AT BIRTH}

Before birth, the lungs are not required for gas exchange, and the airways are filled with a liquid that is critical for growth and development of the fetal lung (7). Pulmonary vascular 


\section{Respiratory support and brain injury $\mid$ Review}

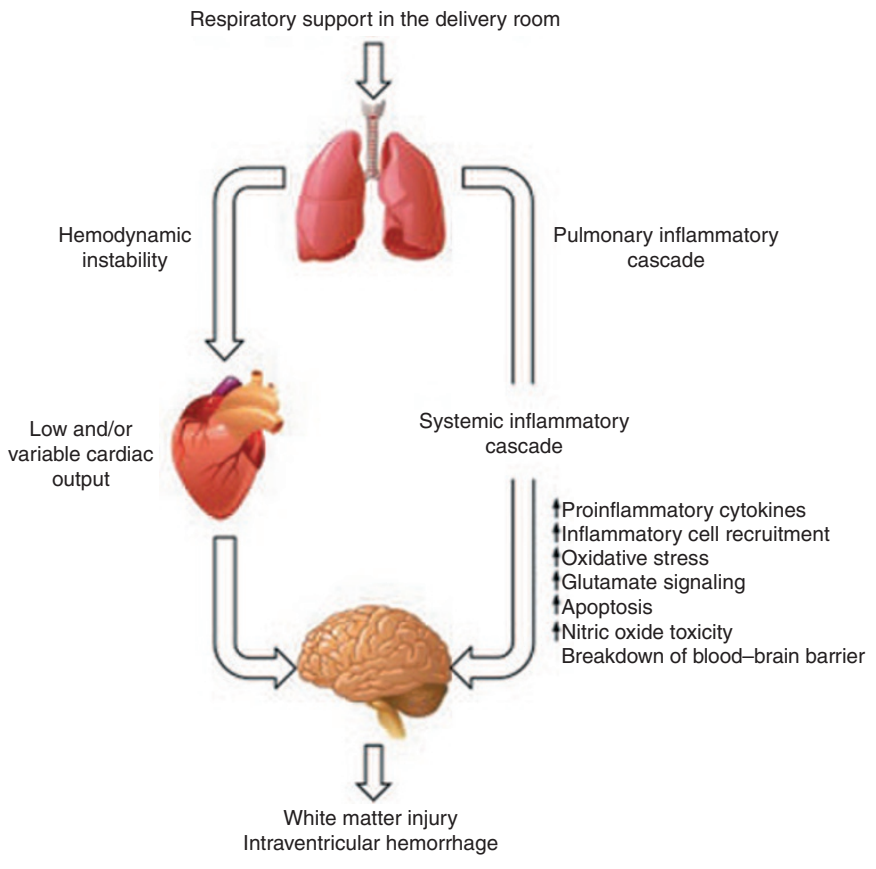

Figure 1. Mechanisms of brain injury induced by the initiation of mechanical ventilation in the delivery room. Hemodynamic instability and the initiation of a systemic proinflammatory cascade can each work independently, or may initiate one another, resulting in adverse pathologies such as intraventricular hemorrhage and/or diffuse white matter injury.

resistance is high, pulmonary blood flow (PBF) is low (8), and $\sim 90 \%$ of right ventricular output bypasses the lungs and flows through the ductus arteriosus (DA) directly into the descending aorta (right-to-left shunting) (8). This results in a unique fetal PBF waveform (Figure 2a), wherein forward flow into the lungs only occurs during the early stages of systole. During late systole and early diastole, blood flow rapidly returns to zero, whereupon a pronounced backflow or retrograde flow occurs resulting from blood flow reflecting off the highly resistant pulmonary vasculature (8).

With the establishment of ventilation or initiation of air breathing at birth, pulmonary vascular resistance decreases, PBF increases, and the entire output of the right ventricle enters the pulmonary circulation (8). The DA begins to close $(8,9)$, but before it does, the direction of shunting through the DA reverses, changing from entirely right to left during fetal life to predominately left to right in the newborn (9). As a result, left ventricular output contributes up to $50 \%$ of PBF immediately after birth, resulting in the maintenance of forward flow into the lungs throughout the cardiac cycle (Figure 2b). Thus, at birth, both left and right ventricles contribute to PBF, which is a normal, albeit transient, event in the neonatal transition (9). This is a critical transitionary process that helps to sustain and stabilize PBF, pulmonary venous return, and left ventricular output immediately after birth (9). What is often overlooked is that stabilizing PBF and, consequently, cardiovascular stability also has critical direct effects on cerebral arterial pressure and CBF during this transition period. Although clinicians have long referred to a "golden hour" in which rapid attainment of cardiovascular stability is the goal and intervention during this
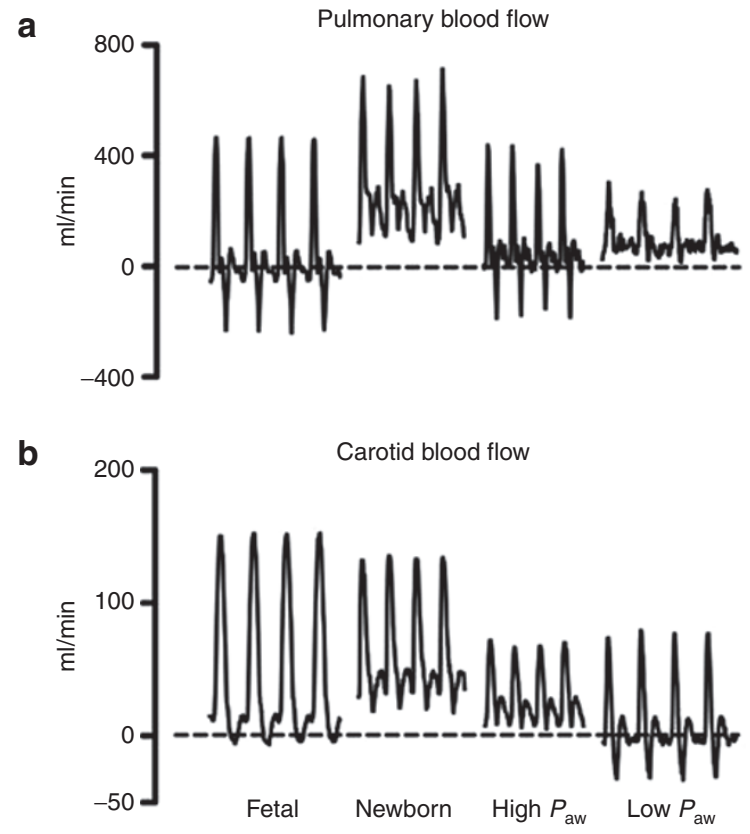

Figure 2. The influence of airway pressure on pulmonary and cerebral blood flow. Real-time traces of (a) pulmonary blood flow measured in the left main pulmonary artery and (b) carotid arterial blood flow in the fetus, newborn, newborn during high airway pressure $\left(P_{\mathrm{aw}}\right)$, and newborn during low (suctioning) airway pressure. Blood flow with values $<0$ represents negative or retrograde blood flow.

period is thought to confer improved outcomes (10), experimental animal research mimicking this transition suggests an interaction between immediate respiratory support, cardiovascular output instability, and the development of cerebral injury.

\section{HEMODYNAMIC CONSEQUENCES OF THE INITIATION OF POSITIVE PRESSURE RESPIRATORY SUPPORT}

The mainstay of postdelivery resuscitation in the neonate is the establishment of respiration, either spontaneous or with positive pressure (11). In the premature infant $(<29 \mathrm{wk}$ gestation), reduced respiratory drive, poorly compliant lungs, and reduced thoracic musculature result in an increased need for early positive pressure support (12). The volume and compliance of the newborn lungs vary dramatically over the first few breaths as lung liquid is absorbed and an air-liquid interface is established at the terminal air sacs (13). Spontaneously breathing infants develop considerable transthoracic pressures over the first few breaths and relatively high positive pressures are required to initiate mechanical ventilation. However, compliance rapidly falls as lung aeration increases, resulting in less pressure requirement to achieve a functional tidal volume $\left(V_{\mathrm{T}}\right)$ with subsequent breaths. Current delivery room resuscitation uses pressure-limited devices that do not effectively measure $V_{\mathrm{T}}$. Clinicians rely on monitoring chest expansion; however, this is a poor indicator of $V_{\mathrm{T}}(14)$, and many infants can receive inappropriate $V_{\mathrm{T}}$ within minutes of birth (15). Alternative strategies have been proposed for aerating lung volume, including sustained initial breaths (16) and a ramped increase in endexpiratory pressure (17). Although such strategies appear 
beneficial in establishing lung gas volumes and decreasing pulmonary compliance, they may be detrimental to the circulation and possibly the immature brain.

Studies in animals and humans show the intrinsic association between mean airway pressure and destabilization of systemic arterial flows and pressures due to altered PBF during the transition at birth (18-21). Increasing airway pressure decreases the alveolar/capillary transmural pressure gradient, causing compression of the intra-alveolar capillaries, which increases pulmonary vascular resistance and decreases PBF (3). Further increases in airway pressure and pulmonary vascular resistance may sustain pulmonary arterial pressures above systemic arterial pressures, potentiating continued right-to-left shunting through the DA (Figure 2). This effect has been demonstrated during different ventilation modalities, including PPV, high-frequency oscillatory ventilation, and high-frequency jet ventilation $(18,20,22,23)$. The effect of high airway pressure is not limited to the pulmonary vasculature, with direct compressive effects observed on the newborn heart, resulting in reduced cardiac performance and ventricular output $(21,24)$. This is further complicated by recent studies in preterm animals $(25,26)$ and preterm infants $(27,28)$ demonstrating that the preterm heart, particularly the myocardium, is structurally immature, translating to lower contractility in the days after birth and an inability to cope with increasing afterload.

At birth, the neonatal circulation transitions from a highvolume low-resistance fetal circulation, due to the presence of the placenta, to a reduced-volume higher-resistance newborn circulation when the cord is clamped. Cardiac output and systemic perfusion are dependent on maintaining preload. Left ventricular preload and output, which are major determinants of $\mathrm{CBF}$, are largely determined by pulmonary venous return (18). Therefore, factors that reduce PBF, such as high positive end-expiratory pressures, also reduce $\mathrm{CBF}$ as indicated by reduced superior vena cava blood flow (18) (representing blood returning from the upper body, including the brain). Similarly, studies in preterm infants have shown that changes to positive end-expiratory pressure can cause clinically significant changes in systemic blood flow (29). Superior vena cava flow is a proxy for overall reduced cardiac output, and low superior vena cava flow in the first $24 \mathrm{~h}$ after birth in preterm infants ( $<29 \mathrm{wk}$ gestation) is strongly associated with cerebral injury, including intraventricular hemorrhage (IVH) and longterm neurodevelopmental disability $(30,31)$.

The removal of mean airway pressure can have the opposite effect. Open tracheal suction soon after birth increased PBF, left ventricular output, systemic arterial pressure, and CBF (32). Removal of positive end-expiratory pressure in preterm infants reduced cerebral blood flow velocity in preterm infants with a patent DA, primarily due to increased ductal stealing, evident by negative $\mathrm{CBF}$ velocities during diastole (example in Figure 2) $(33,34)$. The change in CBF velocities is asymmetric in the carotid arteries, with the greatest effect observed on the left side, probably due to its proximity to the DA (35). If sustained, the "steal" of blood flow from the systemic circulation can reduce cardiac function and overall systemic blood flow, cause excessive pulmonary blood flow, and increase the risk of pulmonary hemorrhage, IVH, or periventricular leukomalacia $(33,34,36)$. Thus, high and low mean airway pressures in an infant with a patent DA can alter CBF, resulting in adverse cerebral outcomes, highlighting the necessity for moderating lung pressures during the initial ventilation.

The influence of ventilation strategy on cardiopulmonary hemodynamics is not restricted to high airway pressure. We recently demonstrated that the initiation of high $V_{\mathrm{T}}$ ventilation for the first $15 \mathrm{~min}$ after birth caused large fluctuations in CBF (Figure 3), impaired cerebral autoregulation (cerebral vasoparalysis), and increased vascular extravasation (leakage), a precursor to cerebral hemorrhage (4). Abnormal fluctuations in $\mathrm{CBF}$ (defined as prolonged swings in CBF, either high or low, for more than 10-20 s) are common in preterm infants (37) and occur as a result of adverse pulmonary, cardiovascular, or systemic (vascular) factors. The majority of abnormal $\mathrm{CBF}$ is due to impaired cardiovascular control (38). Abnormal fluctuations in CBF are not usually a problem in term infants because they have the ability to maintain near-constant blood flow in the face of changing perfusion pressures by altering cerebral vascular resistance (autoregulation) (39). However, preterm infants commonly have episodes of impaired autoregulation, primarily due to immaturity of or injury to the cerebral vascular bed (40). Episodes of impaired autoregulation occur in 87 of 90 premature infants $<30$ wk gestation and may be present $50 \%$ of the time during the first $5 \mathrm{~d}$ after birth (41). The combination of developmental immaturity and an inability to autoregulate CBF can render the preterm neonatal brain susceptible to injury in response to systemic circulatory disturbances occurring as a result of suboptimal ventilation. Indeed, IVH was observed in 21 of 23 infants with respiratory distress, in whom fluctuations in CBF velocity (measured by Doppler ultrasonography) were detected (42).

CBF stability is also critical for maintaining cerebral oxygenation. Indeed, studies of preterm lambs have shown that adverse alterations to pulmonary blood flow can reduce CBF, in addition to oxygen delivery and consumption (43). Studies in preterm infants during the first days of newborn life have shown that changes in cerebral oxygen extraction are associated with IVH $(44,45)$. Cerebral oxygen extraction is inversely correlated to oxygen delivery, and it normally decreases after birth as oxygen availability increases (46). However, clinical trials have demonstrated the presence of high cerebral oxygen extraction and low regional cerebral oxygenation (measured by near-infrared spectroscopy) when left ventricular output is low in the hours to days after birth $(45,47)$ and have demonstrated a strong association with IVH and/or death (45). These studies further highlight the critical link between cardiovascular and cerebral hemodynamics and promote the combination of cardiovascular and cerebral hemodynamic measurements with cerebral oxygenation as a potential early indicator of poor outcome.

Importantly, strategies aimed at optimizing the initial respiratory support in the delivery room have demonstrated improved CBF stability (Figure 3) and cerebral oxygenation, 


\section{Respiratory support and brain injury $\mid$ Review}

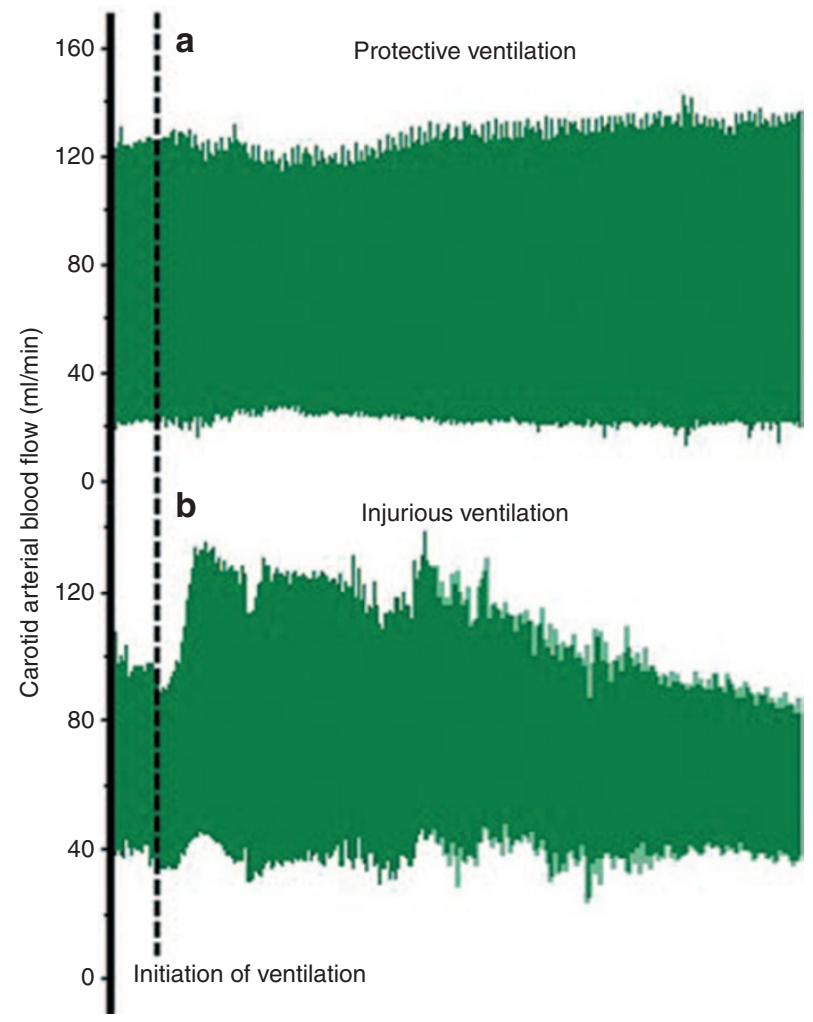

Figure 3. Carotid arterial blood flow before and immediately after the initiation of positive pressure ventilation (PPV) in preterm lambs. The dashed line represents the time when ventilation was initiated. (a) PPV was initiated using a protective ventilation strategy, whereas in (b) an injurious high tidal volume ventilation strategy was used, resulting in cerebral blood flow instability.

apart from reduced vascular permeability (Figure 4) $(4,48)$, suggesting that simply improving the initial respiratory care in the delivery room may reduce brain injury.

Taken together, these findings show that the circulatory transition, which is critical for survival after birth, can be severely compromised by suboptimal respiratory care in preterm neonates. Importantly, due to the interdependence of the cardiopulmonary and cerebral circulations in the acute circulatory transition period, strategies that affect cardiopulmonary hemodynamics can have a direct effect on cerebral hemodynamics, leading to adverse consequences on the brain.

\section{INFLAMMATORY CONSEQUENCES OF THE INITIATION OF RESPIRATORY SUPPORT}

It is well established that five large rapid inflations $(>8 \mathrm{ml} / \mathrm{kg})$ at birth are sufficient to cause lung injury (49) and to initiate a systemic inflammatory cascade in the neonate (50). The bag-and-mask or T-piece circuits commonly used for neonatal resuscitation provide no feedback information on the $V_{\mathrm{T}}$ being delivered. As a consequence, $V_{\mathrm{T}}$ is poorly controlled, potentially exposing the preterm neonate to volutrauma. Indeed, recent studies have found that the $V_{\mathrm{T}}$ delivered during resuscitation in the delivery room using a T-piece device ranged from 0 to $>30 \mathrm{ml} / \mathrm{kg}$, with $85 \%$ of preterm infants receiving excessively high $V_{\mathrm{T}}(>8 \mathrm{ml} / \mathrm{kg})$ (15). Importantly, because the immature
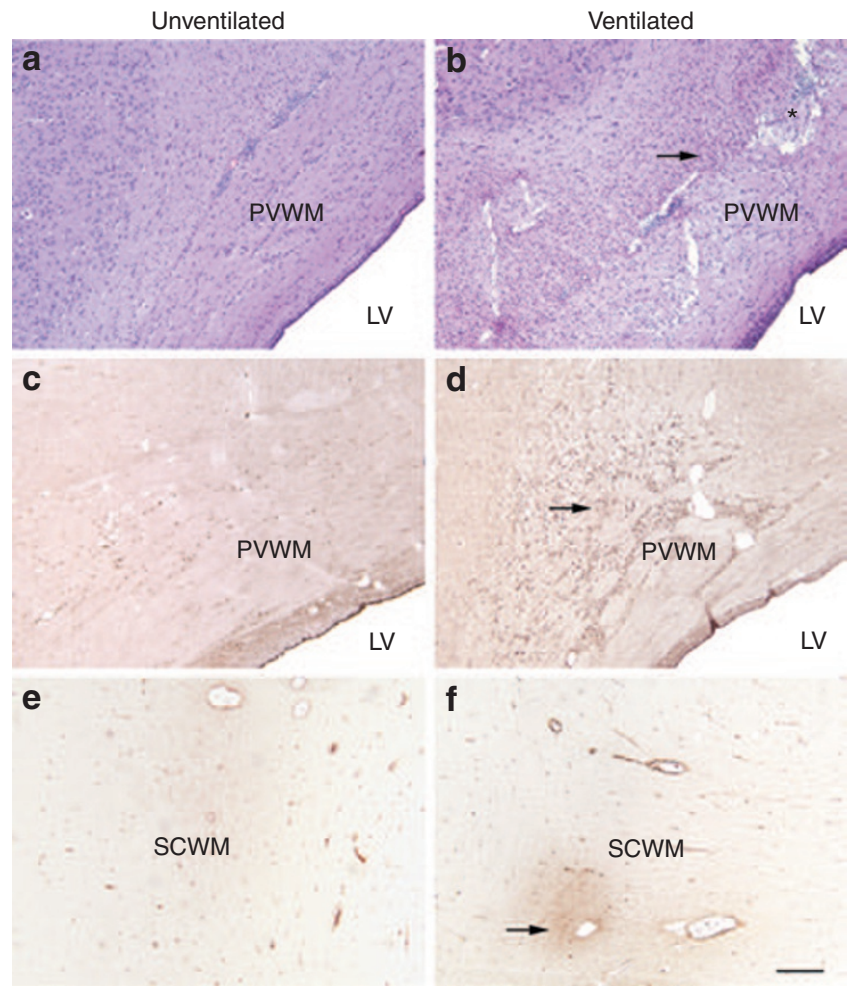

Figure 4. Evidence of white matter injury from positive pressure ventilation. (a, b) Representative hematoxylin-eosin-stained sections; (c, d) lectin-stained sections within the periventricular white matter (PVWM); and $(\mathbf{e}, \mathbf{f})$ albumin immunostaining in the subcortical white matter (SCWM) in an unventilated preterm lamb and a lamb ventilated for $90 \mathrm{~min}$. Evidence of diffuse white matter gliosis (arrow in $\mathbf{b}$ ), white matter lesions (* in b), inflammatory cell infiltration (arrow in $\mathbf{d}$ ), and albumin extravasation (arrow in $\mathbf{f}$ ) in the ventilated preterm lamb, compared with the unventilated lamb (a, c, and e). Bar $=200 \mu \mathrm{m}$. LV, left ventricle.

lung remains partly liquid-filled at birth (51) and because the effective $V_{\mathrm{T}}$ may be considerably reduced, even "safe" levels of $V_{\mathrm{T}}$ may cause regional volutrauma. For example, $5 \mathrm{ml} /$ $\mathrm{kg}$ equates to $15 \mathrm{ml} / \mathrm{kg}$ if only one-third of the lung is aerated and the remaining two-thirds are liquid-filled. Combined with a compliant chest wall, the degree of regional overdistension injury at a given airway pressure may therefore be very large.

PPV of preterm lambs with an initial $V_{\mathrm{T}}$ of $10-12 \mathrm{ml} / \mathrm{kg}$ for $15 \mathrm{~min}$ (normal $V_{\mathrm{T}}$ is $6-8 \mathrm{ml} / \mathrm{kg}$ ) (52) initiated a pulmonary proinflammatory response (53), which in turn initiated a systemic inflammatory cascade (Figure 1$)(50,54,55)$. The acute systemic inflammatory response to PPV was observed in term and late-preterm neonates who displayed increased levels of the proinflammatory cytokines interleukin (IL)-8 (2.5-fold), IL-1 $\beta$ (7.5-fold), and tumor necrosis factor (TNF)- $\alpha$ (10-fold) and decreased levels of the anti-inflammatory cytokine IL-10 (by $90 \%$ ) in plasma only $2 \mathrm{~h}$ after its initiation (56). Considering that systemic proinflammatory cytokines can readily cross the blood-brain barrier $(45,57)$, the circulating cytokines can elicit and exacerbate an inflammatory response within the brain. This can result in increased number of infiltrating inflammatory cells, activation of resident microglia (which causes local amplification of proinflammatory cytokines), increased oxidative stress, and subsequent diffuse white matter gliosis within 
the periventricular white matter, subcortical white matter, and corpus callosum (Figure 4$)(4,58,59)$. This brain inflammatory environment, notably an increase in activated microglial cells, is a prominent feature of neuropathologies and can be correlated with brain cell death (60). As a clinical correlate, diffuse "microstructural" white matter injury within the corpus callosum in infants born at $<33 \mathrm{wk}$ gestation is clinically associated with poor cognitive function at 19 years of age (61). Interestingly, the pattern of white matter injury associated with increased systemic proinflammatory mediators is similar to that described in response to infection/inflammation in animal studies $(58,59,62)$ and is consistent with that in infants with periventricular leukomalacia associated with higher plasma or cerebral spinal fluid cytokine expression (63-65). The inflammatory response of the brain to mechanical ventilation is more common in, but not limited to, the white matter, with PPV in male rats increasing c-fos expression, an indicator of neuronal activation, in gray matter, which was further amplified by high $V_{\mathrm{T}}$ ventilation within the retrosplenial cortex and thalamus (55). Studies in preterm baboons (66) and preterm lambs (67) further demonstrate the association between ventilation strategy and gray matter injury and found reduced severity of injury when less-invasive ventilation strategies were used.

Increased systemic proinflammatory cytokines not only cause direct cerebral injury but may also alter postnatal hemodynamics as cord blood IL-6 levels are inversely related to systolic, mean, and diastolic blood pressures (68). Increased circulatory disturbances in the first $24 \mathrm{~h}$ of life are evident in extremely preterm infants exposed to fetal inflammation (69). Lower cerebral vascular resistance, vasodilatation, higher CBF velocities, and increased incidence of intracranial hemorrhage were observed in babies with early-onset neonatal sepsis (70). Hemodynamic disturbance and subsequent cerebral white matter injury are observed in preterm lambs that have been exposed to inflammatory stimuli and that mount a systemic inflammatory response $(58,71,72)$. Thus, we suggest a progressive series of events that begins with initiation of suboptimal ventilation, which in turn stimulates a systemic proinflammatory cascade and may then directly result in inflammation-induced white matter injury or indirectly cause white matter injury through initiation of hemodynamic instability. Importantly, a recent study demonstrated that optimizing the initial respiratory support at birth in preterm lambs reduced the initiation of a systemic inflammatory cascade and improved the subsequent brain inflammation and injury (4). This indicates that it is not ventilation per se that is injurious but the poorly controlled use of PPV in the delivery room that can significantly increase the risk of brain injury.

\section{CLINICAL PERSPECTIVE}

The relationship between the intensity of the immediate resuscitation and the subsequent long-term outcomes in preterm infants is difficult to assess. In the clinical setting, the underlying need for resuscitation is associated with an increased risk for neurodevelopmental deficits, and it is difficult to separate the brain injury and inflammation that occurs within the delivery room from events that occur during the days to months of subsequent intensive care. In very-low-birth-weight infants enrolled in the Caffeine for Apnea of Prematurity trial, the rates of many of the primary outcomes, including bronchopulmonary dysplasia, brain injury, and cerebral palsy at 18 months, increased with increasing levels of delivery room resuscitation (73). However, only the risk of bronchopulmonary dysplasia remained significant when the data were adjusted for prognostic variables. Data from the Vermont Oxford Network (74) and a meta-analysis by Shah et al. (75). showed that very-lowbirth-weight infants who received cardiopulmonary resuscitation had increased mortality and higher rates of IVH compared with infants who did not require resuscitation. Trials that have compared early continuous positive airway pressure vs. early surfactant and intubation treatment have shown trends for higher rates of bronchopulmonary dysplasia or death in the intubated groups $(76,77)$ but have failed to find differences in neurodevelopmental outcomes (78). Indeed, studies in preterm lambs have also found no difference in terms of lung and systemic inflammation and injury between continuous positive airway pressure and PPV (79); therefore, the findings from these trials are not surprising. Thus appropriate animal studies are well placed to identify the individual contribution of different aspects of neonatal care to brain injury, separating out respiratory, cardiovascular, and inflammatory etiology, in addition to facilitating the understanding of the time frames in which each of these contributors act. This will allow development and testing of strategies that are most likely to reduce ventilator-induced brain injury in preterm infants before the conduct of appropriately designed, targeted clinical trials, thereby increasing the chances of showing a clear benefit of specific interventions such as improved delivery room resuscitation strategies.

\section{SUMMARY}

The initiation of ventilation of the preterm infant in the delivery room is likely to be critical for his/her survival. However, recent studies have shown that poorly controlled ventilation can lead to brain injury through hemodynamic instability and/or the activation of proinflammatory pathways. This early interdependence of the pulmonary, cardiovascular, and cerebral circulations, particularly in the transitional period of a preterm infant, is not well understood and may be overlooked when individual organ systems are under investigation. Recent studies have emphasized the importance of the link between the lung, heart, and brain in the transitioning preterm infant. Thus, at this critical time of preterm delivery, clinical interventions only focusing on improved respiratory outcomes can have unanticipated downstream consequences on the developing brain. Considering that the initiation of respiratory support in the delivery room is often poorly monitored or controlled, we urgently need to consider optimal resuscitation strategies that are measured against both cerebral and cardiopulmonary outcomes.

\section{STATEMENT OF FINANCIAL SUPPORT}

This research was supported by the Cerebral Palsy Alliance of Australia, Heart Research Australia, National Health and Medical Research Council Research 


\section{Respiratory support and brain injury $\mid$ ReVieW}

Fellowships (G.R.P.: 1026890 and S.B.H.: 545921), a Rebecca L. Cooper Medical Research Foundation Fellowship (G.R.P.), and the Victorian Government's Operational Infrastructure Support Program.

Disclosure: The authors do not have any financial ties with the products mentioned in the study or potential/perceived conflicts of interest to declare.

\section{REFERENCES}

1. Chow SSW. Report of the Australian and New Zealand Neonatal Network 2010. Sydney, Australia: ANZNN, 2013.

2. Jobe $A H$, Ikegami M. Lung development and function in preterm infants in the surfactant treatment era. Annu Rev Physiol 2000;62:825-46.

3. Polglase GR, Hooper SB. Role of intra-luminal Pressure in Regulating PBF in the Fetus and After Birth. Curr Ped Rev 2006;2:287-99.

4. Polglase GR, Miller SL, Barton SK, et al. Initiation of resuscitation with high tidal volumes causes cerebral hemodynamic disturbance, brain inflammation and injury in preterm lambs. PLoS ONE 2012;7:e39535.

5. Lopez-Aguilar J, Fernandez-Gonzalo MS, Turon M, et al. Lung-brain interaction in the mechanically ventilated patient. Med Intensiva 2013;37:485-92.

6. Quílez ME, López-Aguilar J, Blanch L. Organ crosstalk during acute lung injury, acute respiratory distress syndrome, and mechanical ventilation. Curr Opin Crit Care 2012;18:23-8.

7. Hooper SB, Harding R. Fetal lung liquid: a major determinant of the growth and functional development of the fetal lung. Clin Exp Pharmacol Physiol 1995;22:235-47.

8. Rudolph AM. Fetal and neonatal pulmonary circulation. Annu Rev Physiol 1979;41:383-95.

9. Crossley KJ, Allison BJ, Polglase GR, Morley CJ, Davis PG, Hooper SB. Dynamic changes in the direction of blood flow through the ductus arteriosus at birth. J Physiol (Lond) 2009;587(Pt 19):4695-704.

10. Doyle KJ, Bradshaw WT. Sixty golden minutes. Neonatal Netw 2012;31:289-94.

11. Kattwinkel J, Perlman JM, Aziz K, et al. Part 15: neonatal resuscitation: 2010 American Heart Association Guidelines for Cardiopulmonary Resuscitation and Emergency Cardiovascular Care. Circulation 2010;122(18 Suppl 3):S909-19.

12. Hoskyns EW, Milner AD, Boon AW, Vyas H, Hopkin IE. Endotracheal resuscitation of preterm infants at birth. Arch Dis Child 1987;62:663-6.

13. Boon AW, Milner AD, Hopkin IE. Lung volumes and lung mechanics in babies born vaginally and by elective and emergency lower segmental cesarean section. J Pediatr 1981;98:812-5.

14. Poulton DA, Schmölzer GM, Morley CJ, Davis PG. Assessment of chest rise during mask ventilation of preterm infants in the delivery room. Resuscitation 2011;82:175-9.

15. Schmölzer GM, Kamlin OC, O’Donnell CP, Dawson JA, Morley CJ, Davis PG. Assessment of tidal volume and gas leak during mask ventilation of preterm infants in the delivery room. Arch Dis Child Fetal Neonatal Ed 2010;95:F393-7.

16. Milner A. The importance of ventilation to effective resuscitation in the term and preterm infant. Semin Neonatol 2001;6:219-24.

17. Pellicano A, Tingay DG, Mills JF, Fasulakis S, Morley CJ, Dargaville PA. Comparison of four methods of lung volume recruitment during high frequency oscillatory ventilation. Intensive Care Med 2009;35:1990-8.

18. Polglase GR, Hooper SB, Gill AW, et al. Cardiovascular and pulmonary consequences of airway recruitment in preterm lambs. J Appl Physiol 2009;106:1347-55.

19. Kluckow M, Evans N. Relationship between blood pressure and cardiac output in preterm infants requiring mechanical ventilation. J Pediatr 1996;129:506-12.

20. Polglase GR, Moss TJ, Nitsos I, Allison BJ, Pillow JJ, Hooper SB. Differential effect of recruitment maneuvres on pulmonary blood flow and oxygenation during HFOV in preterm lambs. J Appl Physiol 2008;105:603-10.

21. Mirro R, Busija D, Green R, Leffler C. Relationship between mean airway pressure, cardiac output, and organ blood flow with normal and decreased respiratory compliance. J Pediatr 1987;111:101-6.

22. Musk GC, Polglase GR, Bunnell JB, et al. High positive end-expiratory pressure during high-frequency jet ventilation improves oxygenation and ventilation in preterm lambs. Pediatr Res 2011;69:319-24.
23. Polglase GR, Morley CJ, Crossley KJ, et al. Positive end-expiratory pressure differentially alters pulmonary hemodynamics and oxygenation in ventilated, very premature lambs. J Appl Physiol 2005;99:1453-61.

24. Biondi JW, Schulman DS, Soufer R, et al. The effect of incremental positive end-expiratory pressure on right ventricular hemodynamics and ejection fraction. Anesth Analg 1988;67:144-51.

25. Eiby YA, Lumbers ER, Headrick JP, Lingwood BE. Left ventricular output and aortic blood flow in response to changes in preload and afterload in the preterm piglet heart. Am J Physiol Regul Integr Comp Physiol 2012;303:R769-77.

26. Bensley JG, Stacy VK, De Matteo R, Harding R, Black MJ. Cardiac remodelling as a result of pre-term birth: implications for future cardiovascular disease. Eur Heart J 2010;31:2058-66.

27. Barrington KJ. Hypotension and shock in the preterm infant. Semin Fetal Neonatal Med 2008;13:16-23.

28. Takahashi Y, Harada K, Kishkurno S, Arai H, Ishida A, Takada G. Postnatal left ventricular contractility in very low birth weight infants. Pediatr Cardiol 1997;18:112-7.

29. de Waal KA, Evans N, Osborn DA, Kluckow M. Cardiorespiratory effects of changes in end expiratory pressure in ventilated newborns. Arch Dis Child Fetal Neonatal Ed 2007;92:F444-8.

30. Miletin J, Dempsey EM. Low superior vena cava flow on day 1 and adverse outcome in the very low birthweight infant. Arch Dis Child Fetal Neonatal Ed 2008;93:F368-71.

31. Kluckow M, Evans N. Low superior vena cava flow and intraventricular haemorrhage in preterm infants. Arch Dis Child Fetal Neonatal Ed 2000;82:F188-94.

32. Galinsky R, Moss TJ, Polglase GR, Hooper SB. Intrauterine inflammation alters cardiopulmonary but not cerebral hemodynamics during open endotracheal tube suction in preterm lambs. Pediatr Res 2013;74:48-53.

33. Mullaart RA, Hopman JC, Rotteveel JJ, et al. Influence of end expiratory pressure on cerebral blood flow in preterm infants. Early Hum Dev 1995;40:157-65.

34. Shortland DB, Gibson NA, Levene MI, Archer LN, Evans DH, Shaw DE. Patent ductus arteriosus and cerebral circulation in preterm infants. Dev Med Child Neurol 1990;32:386-93.

35. Mullaart RA, Daniëls O, Hopman JC, de Haan AF, Stoelinga GB, Rotteveel JJ. Asymmetry of the cerebral blood flow: an ultrasound Doppler study in preterm newborns. Pediatr Neurol 1995;13:319-22.

36. Baylen BG, Ogata H, Ikegami M, Jacobs HC, Jobe AH, Emmanouilides GC. Left ventricular performance and regional blood flows before and after ductus arteriosus occlusion in premature lambs treated with surfactant. Circulation 1983;67:837-43.

37. Gilmore MM, Stone BS, Shepard JA, Czosnyka M, Easley RB, Brady KM Relationship between cerebrovascular dysautoregulation and arterial blood pressure in the premature infant. J Perinatol 2011;31:7229.

38. Del Toro J, Louis PT, Goddard-Finegold J. Cerebrovascular regulation and neonatal brain injury. Pediatr Neurol 1991;7:3-12.

39. Wong FY, Leung TS, Austin T, et al. Impaired autoregulation in preterm infants identified by using spatially resolved spectroscopy. Pediatrics 2008;121:e604-11.

40. Greisen G. Autoregulation of cerebral blood flow in newborn babies. Early Hum Dev 2005;81:423-8.

41. Soul JS, Hammer PE, Tsuji M, et al. Fluctuating pressure-passivity is common in the cerebral circulation of sick premature infants. Pediatr Res 2007;61:467-73

42. Perlman JM, McMenamin JB, Volpe JJ. Fluctuating cerebral blood-flow velocity in respiratory-distress syndrome. Relation to the development of intraventricular hemorrhage. N Engl J Med 1983;309:204-9.

43. Andersen CC, Pillow JJ, Gill AW, et al. The cerebral critical oxygen threshold of ventilated preterm lambs and the influence of antenatal inflammation. J Appl Physiol 2011;111:775-81.

44. Kissack CM, Garr R, Wardle SP, Weindling AM. Postnatal changes in cerebral oxygen extraction in the preterm infant are associated with intraventricular hemorrhage and hemorrhagic parenchymal infarction but not periventricular leukomalacia. Pediatr Res 2004;56:111-6. 
45. Noori S, McCoy M, Anderson MP, Ramji F, Seri I. Changes in cardiac function and cerebral blood flow in relation to peri/intraventricular hemorrhage in extremely preterm infants. J Pediatr 2013;30:45.

46. Kissack CM, Garr R, Wardle SP, Weindling AM. Cerebral fractional oxygen extraction is inversely correlated with oxygen delivery in the sick, newborn, preterm infant. J Cereb Blood Flow Metab 2005; 25:545-53.

47. Kissack CM, Garr R, Wardle SP, Weindling AM. Cerebral fractional oxygen extraction in very low birth weight infants is high when there is low left ventricular output and hypocarbia but is unaffected by hypotension. Pediatr Res 2004;55:400-5.

48. Sobotka KS, Hooper SB, Allison BJ, et al. An initial sustained inflation improves the respiratory and cardiovascular transition at birth in preterm lambs. Pediatr Res 2011;70:56-60.

49. Björklund LJ, Ingimarsson J, Curstedt $\mathrm{T}$, et al. Manual ventilation with a few large breaths at birth compromises the therapeutic effect of subsequent surfactant replacement in immature lambs. Pediatr Res 1997;42:348-55.

50. Hillman NH, Moss TJ, Kallapur SG, et al. Brief, large tidal volume ventilation initiates lung injury and a systemic response in fetal sheep. Am J Respir Crit Care Med 2007;176:575-81.

51. Wallace MJ, Hooper SB, Harding R. Effects of elevated fetal cortisol concentrations on the volume, secretion, and reabsorption of lung liquid. Am J Physiol 1995;269(4 Pt 2):R881-7.

52. Schmölzer GM, Te Pas AB, Davis PG, Morley CJ. Reducing lung injury during neonatal resuscitation of preterm infants. J Pediatr 2008;153:741-5.

53. Polglase GR, Hillman NH, Pillow JJ, et al. Positive end-expiratory pressure and tidal volume during initial ventilation of preterm lambs. Pediatr Res 2008;64:517-22.

54. Chiumello D, Pristine G, Slutsky AS. Mechanical ventilation affects local and systemic cytokines in an animal model of acute respiratory distress syndrome. Am J Respir Crit Care Med 1999;160:109-16.

55. Quilez ME, Fuster G, Villar J, et al. Injurious mechanical ventilation affects neuronal activation in ventilated rats. Crit Care 2011;15:R124.

56. Bohrer B, Silveira RC, Neto EC, Procianoy RS. Mechanical ventilation of newborns infant changes in plasma pro- and anti-inflammatory cytokines. J Pediatr 2010;156:16-9.

57. Threlkeld SW, Lynch JL, Lynch KM, Sadowska GB, Banks WA, Stonestreet BS. Ovine proinflammatory cytokines cross the murine blood-brain barrier by a common saturable transport mechanism. Neuroimmunomodulation 2010;17:405-10.

58. Polglase GR, Nitsos I, Baburamani AA, et al. Inflammation in utero exacerbates ventilation-induced brain injury in preterm lambs. J Appl Physiol 2012;112:481-9.

59. Khwaja O, Volpe JJ. Pathogenesis of cerebral white matter injury of prematurity. Arch Dis Child Fetal Neonatal Ed 2008;93:F153-61.

60. Yawno T, Schuilwerve J, Moss TJ, et al. Human amnion epithelial cells reduce fetal brain injury in response to intrauterine inflammation. Dev Neurosci 2013;35:272-82.

61. Allin MP, Kontis D, Walshe M, et al. White matter and cognition in adults who were born preterm. PLoS ONE 2011;6:e24525.

62. Nitsos I, Rees SM, Duncan J, et al. Chronic exposure to intra-amniotic lipopolysaccharide affects the ovine fetal brain. J Soc Gynecol Investig 2006;13:239-47.
63. Goepfert AR, Andrews WW, Carlo W, et al. Umbilical cord plasma interleukin- 6 concentrations in preterm infants and risk of neonatal morbidity. Am J Obstet Gynecol 2004;191:1375-81.

64. Viscardi RM, Muhumuza CK, Rodriguez A, et al. Inflammatory markers in intrauterine and fetal blood and cerebrospinal fluid compartments are associated with adverse pulmonary and neurologic outcomes in preterm infants. Pediatr Res 2004;55:1009-17.

65. Volpe JJ. Postnatal sepsis, necrotizing entercolitis, and the critical role of systemic inflammation in white matter injury in premature infants. J Pediatr 2008;153:160-3.

66. Loeliger M, Inder T, Cain S, et al. Cerebral outcomes in a preterm baboon model of early versus delayed nasal continuous positive airway pressure. Pediatrics 2006;118:1640-53.

67. Albertine $\mathrm{KH}$. Brain injury in chronically ventilated preterm neonates: collateral damage related to ventilation strategy. Clin Perinatol 2012;39:727-40.

68. Yanowitz TD, Jordan JA, Gilmour CH, et al. Hemodynamic disturbances in premature infants born after chorioamnionitis: association with cord blood cytokine concentrations. Pediatr Res 2002;51:310-6.

69. Furukawa S, Sameshima H, Ikenoue T. Circulatory disturbances during the first postnatal 24 hours in extremely premature infants 25 weeks or less of gestation with histological fetal inflammation. J Obstet Gynaecol Res 2008;34:27-33.

70. Basu S, Dewangan S, Shukla RC, Anupurva S, Kumar A. Cerebral blood flow velocity in early-onset neonatal sepsis and its clinical significance. Eur J Pediatr 2012;171:901-9.

71. Saito M, Matsuda T, Okuyama K, et al. Effect of intrauterine inflammation on fetal cerebral hemodynamics and white-matter injury in chronically instrumented fetal sheep. Am J Obstet Gynecol 2009;200:663.e1-11.

72. Polglase GR, Hooper SB, Gill AW, et al. Intrauterine inflammation causes pulmonary hypertension and cardiovascular sequelae in preterm lambs. J Appl Physiol 2010;108:1757-65.

73. DeMauro SB, Roberts RS, Davis P, Alvaro R, Bairam A, Schmidt B; Caffeine for Apnea of Prematurity Trial Investigators. Impact of delivery room resuscitation on outcomes up to 18 months in very low birth weight infants. J Pediatr 2011;159:546-50.e1.

74. Finer NN, Horbar JD, Carpenter JH. Cardiopulmonary resuscitation in the very low birth weight infant: the Vermont Oxford Network experience. Pediatrics 1999;104(3 Pt 1):428-34.

75. Shah PS. Extensive cardiopulmonary resuscitation for VLBW and ELBW infants: a systematic review and meta-analyses. J Perinatol 2009;29:655-61.

76. Carlo WA, Finer NN, Walsh MC, et al.; SUPPORT Study Group of the Eunice Kennedy Shriver NICHD Neonatal Research Network. Target ranges of oxygen saturation in extremely preterm infants. N Engl J Med 2010;362:1959-69.

77. Morley CJ, Davis PG, Doyle LW, Brion LP, Hascoet JM, Carlin JB; COIN Trial Investigators. Nasal CPAP or intubation at birth for very preterm infants. N Engl J Med 2008;358:700-8.

78. Vaucher YE, Peralta-Carcelen M, Finer NN, et al.; SUPPORT Study Group of the Eunice Kennedy Shriver NICHD Neonatal Research Network. Neurodevelopmental outcomes in the early CPAP and pulse oximetry trial. N Engl J Med 2012;367:2495-504.

79. Polglase GR, Hillman NH, Ball MK, et al. Lung and systemic inflammation in preterm lambs on continuous positive airway pressure or conventional ventilation. Pediatr Res 2009;65:67-71. 